\title{
The Moderating Effect of Debates on Political Attitudes*
}

\author{
Sarah Brierley $^{\dagger} \quad$ Eric Kramon ${ }^{\ddagger} \quad$ George Kwaku Ofosu ${ }^{\S}$ \\ April 26, 2019
}

Short title for running header: The Moderating Effect of Debates

Keywords: Political partisanship, African elections, Voting Behavior, Political Campaigns, Candidate Debates

${ }^{*}$ The authors gratefully acknowledge funding from the International Growth Centre and the APSA Centennial Center. Many thanks to the Center for Democratic Development in Ghana, and especially to Franklin Oduro, Regina Oforiwaa Amanfo, Samuel Baaye, and Mohammed Awal for their collaboration and facilitation of the project. We thank Samuel Kweku Yamoah for helping us to field the survey. We are also grateful to the team of research enumerators who conducted the surveys. Miguel Pereira provided excellent research assistance. Thanks to Darin Christensen, John Sides, and Lynn Vavreck for their feedback on the research design. Prior versions of this paper were presented at the African Studies Association annual conference in Chicago, November 2017, the Midwest Group in African Political Economy meeting at Northwestern University in December, 2017, and the Evidence in Governance and Politics meeting at Vanderbilt University in February, 2018. We are also grateful for feedback from Mai Hassan and from seminar participants at the Inter-American Development Bank and the London School of Economics. A pre-analysis plan for the study was registered on the Evidence in Governance and Politics registry and can be found here: http://egap.org/registration/2286. The videos and full transcripts of the debates analyzed in this study can be found here: https://sites.google.com/view/ghanadebates/. The study received IRB approval from George Washington University and UCLA.

${ }^{\dagger}$ Department of Political Science, Washington University in St Louis. Mailing address: One Brookings Drive, St. Louis, MO 63130-4899. Email: sabrierley@wustl.edu.

${ }^{\dagger}$ Department of Political Science, George Washington University. Mailing address: 2115 G St NW, Room 440, Washington DC 20052. Email: ekramon@gwu. edu.

${ }^{\S}$ Department of Political Science, Washington University in St Louis. Mailing address: One Brookings Drive, St. Louis, MO 63130-4899. Email: gofosu@wustl. edu. 


\begin{abstract}
In theory, candidate debates can influence voters by providing information about candidates' quality and policy positions. However, there is limited evidence about whether and why debates influence voters in new democracies. We use a field experiment on parliamentary debates during Ghana's 2016 elections to show that debates improve voters' evaluations of candidates. Debates have the strongest effect on partisan voters, who become more favorable toward and more likely to vote for opponentparty candidates and less likely to vote for co-partisans. Experimental and unique observational data capturing participants' second-by-second reactions to the debates show that policy information was the most important causal mechanism driving partisan moderation, especially among strong partisans. A follow-up survey shows that these effects persist in electorally competitive communities, while they dissipate in party strongholds. Policy-centered debates have the potential to reduce partisan polarization in new democracies, but the local political context conditions the persistence of these effects.
\end{abstract}

Replication Materials: The data, code, and any additional materials required to replicate all analyses in this article are available on the American Journal of Political Science Dataverse within the Harvard Dataverse Network, at: https://doi.org/10.7910/DVN/OJA7YS.

Word Count: 9,964 
Candidate debates are an increasingly prevalent aspect of electoral campaigns around the world. ${ }^{1}$ Yet we lack evidence on how they influence voters in new democracies. On the one hand, debates could help citizens choose representatives based on their qualifications or policy positions, which may enhance accountability (Besley, 2006). Alternatively, debates could reinforce ethnic voting or encourage voters to evaluate politicians on the basis of their appearance (Lawson et al., 2010). Further, it is unknown whether, in the context of newer democracies, debates moderate partisan opinions or polarize the electorate by entrenching the preferences of partisan voters (Levendusky, 2013).

To address the fundamental questions of whether and why debates influence voters, we conducted a field experiment analyzing the impact of parliamentary debates held ahead of Ghana's 2016 elections. $^{2}$ The debates, organized by Ghana's National Commission for Civic Education (NCCE) and the Center for Democratic Development (CDD-Ghana), included all of the parliamentary candidates competing in the constituencies where we conducted the research. ${ }^{3}$ The debates were real locally organized campaign events, which enhances the external validity of the study. Candidates were in the same location, answered the same questions, and engaged with their competitors; in short, they were similar to debates held in older democracies, including the United States. We videotaped the debates in three electoral constituencies and randomly assigned study participants $(\mathrm{N}=1,991)$ to view either the debate or a control video; we surveyed them immediately afterward. To determine whether the effects of the debate persisted, we conducted a follow-up survey two days later with a randomly selected subsample.

We argue that debates could influence voters through two theoretical channels: information about candidates' quality and information about candidates' policy positions. To assess these causal mechanisms, the debates were organized into a personal background segment, in which candidates did not discuss policies but could convey information about their quality, and a policy segment, in which candidates discussed education and unemployment policy. We randomly assigned participants to view either only the personal background segment, only the policy segment, or the whole debate. To assess the importance of physical attributes, which could be interpreted as a signal of candidate quality (Lawson

\footnotetext{
${ }^{1}$ Debates are conducted in over 60 countries, including Cambodia, Canada, Colombia, Ghana, Haiti, Kenya, Liberia, Iraq, Peru, Sierra Leone, and the USA (National Democratic Institute, 2014).

${ }^{2}$ Our hypotheses, measurement strategies, and analyses were pre-specified in a pre-analysis plan. Table A in the Appendix (pg. 1) details all pre-specified hypotheses and associated results.

${ }^{3}$ The NCCE is a constitutionally mandated, non-partisan institution, and CDD-Ghana is a non-governmental organization.
} 
et al., 2010), we also randomly assigned some participants to watch the debates and others to listen to them. By comparing the effects of these separate treatment arms, we can make inferences about causal mechanisms. Further, to gain an in-depth understanding of how debates can shape voter attitudes, we also collected unique observational data that captures participants' real-time, second-by-second positive and negative reactions to the debates. Using these data, we identify the specific moments that generated reactions from participants.

We show that debates do influence voters - by improving their evaluations of candidates. The experimental data suggests that this effect is driven by information about both candidates' personal qualities and their policy positions. We find no evidence that physical attributes or visual cues are important.

We further show that debates have the largest impact on partisans and no average effect on swing voters. Rather than entrenching their pre-existing preferences, the debates made partisan voters more favorable to opposition politicians and less likely to want to vote for their party's candidate. In short, the debates moderated political attitudes. Regarding the causal mechanisms driving the moderation effect, the experimental evidence demonstrates that policy-centered information is of greater importance than information on quality, particularly among the most strongly committed partisans. Consistent with this, the real-time response data shows that partisans were highly polarized in their reactions to the personal background segment — providing positive reactions to co-partisans and negative reactions to other candidates. In the policy segments, this partisan polarization decreased substantially.

Finally, we show that the moderation effect persisted among partisans who live in electorally competitive communities; the effect dissipates among those who live in politically homogeneous communities. This finding highlights that while debates may promote political moderation in the short term, the political context of a voter's local community conditions the durability of the effect.

With these results, we make three novel contributions. First, we contribute to the literature on how partisan identities shape voter responsiveness to political information (Taber and Lodge, 2006). The American politics literature suggests that swing voters and those with weak partisan attachments are more likely to be influenced by debates (Geer, 1988; Hillygus and Jackman, 2003). However, prior research on debates in new democracies has been unable to detect differences between swing and partisan voters. ${ }^{4}$

\footnotetext{
${ }^{4}$ Bidwell, Casey and Glennerster (2016) was statistically underpowered to detect differences in effects between swing and partisan voters.
} 
Our finding that debates moderated the attitudes of strong partisans implies that debates may have different effects in older versus newer democracies. We suggest two related explanations for this result. First, because partisans hold strong negative prior evaluations of their opponent-party candidates, debates may provide surprising and convincing policy information that can encourage moderation, consistent with a model of Bayesian information processing. Second, because partisanship in newer democracies is often not ideologically anchored and more fluid, voters may not engage in partisan motivated reasoning when evaluating the information debates convey. Thus, partisans in these contexts may be open to new information about opposition candidates, especially information about policy positions.

Second, our focus on causal mechanisms advances the literature on candidate debates and candidate-centered events in developing countries. Consistent with other studies, we show that these types of campaign events can impact voter preferences (Fujiwara and Wantchekon, 2013; Wantchekon et al., 2017; Bidwell, Casey and Glennerster, 2016; Platas and Raffler, 2018). We advance this literature with experimental and unique observational data that speaks to why debates impact voters. Understanding causal mechanisms is important because of their theoretical and normative implications for the role of debates in democratic elections. ${ }^{5}$

Finally, the study contributes to the literature on candidate messages and voter behavior in new democracies (Cruz et al., 2018). Existing research suggests that political parties in sub-Saharan Africa tend to rely on valence appeals to attract votes (Bleck and Van de Walle, 2013; Lupu and Riedl, 2013) — non-contentious policies such as a commitment to improving living standards. By contrast, we show that debates motivate parliamentary aspirants to stake out distinct positions concerning how they plan to achieve developmental goals in their constituencies. Importantly, we provide evidence that voters are responsive to policy-specific campaign appeals.

\footnotetext{
${ }^{5}$ Bidwell, Casey and Glennerster (2016) also attempt to distinguish the policy mechanism from personal background mechanism. They do so by presenting participants with news reports that discuss the policy contents of the debates and "get to know you" videos that focus on the candidates' personal attributes. This design simultaneously alters the content and the delivery format. In comparison, we hold the debate format constant and change only the content in order to determine whether differences in content drive differences in effects.
} 


\section{Theoretical Background and Hypotheses}

The theoretical literature on political accountability highlights that voters often judge political candidates along two dimensions: their policy positions and their quality (Besley, 2006). Voters in many new democracies struggle to access credible information about candidates along these dimensions (Pande, 2011), which can make it difficult for voters to hold leaders accountable and select better representatives.

Candidate debates are campaign events that, in principle, can give voters access to information about both candidate quality and policy positions. They do so in a way that is distinct from other types of campaign events, such as campaign rallies. For example, the structure of debates forces candidates to discuss similar topics under the same time constraints, which allows voters to directly compare candidates. Debates also allow candidates to directly engage with their opponents' arguments and positions, which exposes voters to competing arguments and justifications for different policy positions. Since voters in many new democracies lack access to the types of information about candidates that debates convey, we expect that, on average, debates have a positive effect on voters' evaluations of candidates who participate in them $(H 1){ }^{6}$

\subsection{Why Do Debates Influence Voters?}

Debates may influence voters through two distinct, though not mutually exclusive, causal channels: information about candidate quality and information about candidates' policy positions. While policy refers to specific positions, goals, and plans, quality refers to characteristics associated with the candidate's ability to achieve these goals.

Regarding quality, candidates can use debates to convey a range of information about themselves, including their level of education, moral character, and capacity as a leader. In the context of legislative elections, this information can enable voters to determine how successfully candidates can accomplish the main tasks of legislators: to legislate and represent constituency needs, to oversee the executive, and to deliver constituency service (Lindberg, 2010). Knowledge of these individual qualities can help voters evaluate how well legislators will do at implementing important tasks such as providing or lobbying the

\footnotetext{
${ }^{6}$ To be consistent with past studies, we also hypothesized that debates would have a bigger impact for candidates who performed well, and for minor and opposition party candidates. We present these results in Appendix H (pg. 17).
} 
government for local public infrastructure, raising the plight of constituents on the floor of parliament, and holding the government to account. Because debates can provide this information, we hypothesize that debates influence voters because they provide information about candidates' quality, such as their qualifications, competence, and trustworthiness (H2).

In addition, debates could influence voters through non-verbal (visual) signals and forms of communication. For instance, some candidates may be more physically attractive or visually charismatic, which voters may implicitly (and often incorrectly) interpret as a signal of candidate quality (Lawson et al., 2010). We thus test the hypothesis that debates influence voters because of non-verbal signals and communication (H3).

Debates also provide a forum for candidates to outline their policy positions. The African politics literature highlights that political parties and candidates often prefer to communicate their policy messages through valence appeals; that is, by couching their messages in terms that almost no one could disagree with, for example by "[saying] they are for something good (like development, education, democratic practices) or against something bad (like corruption or colonial interference)" (Bleck and Van de Walle, 2013, 1414).

However, because valence appeals can make it hard for voters to differentiate between candidates on programmatic grounds, debates may incentivize candidates to stake out specific policy positions to distinguish themselves from their competitors. Voters in new democracies may be particularly receptive to policies that promote the provision of local public goods, for example, schools, and health clinics (Lindberg, 2010). In the debates that we study, although candidates did make valence appeals, they also tried to draw policy distinctions from one another by making specific policy promises. For example, both major parties made the valence appeal of promising to expand access to secondary education. However, the debates revealed real differences in the two parties' policy plans for achieving this objective: one advocated investments in infrastructure and the other a plan to eliminate secondary school fees. We thus test the hypothesis that debates influence voters because they provide information about candidates' policy positions (H4). 


\subsection{Which Types of Voters Are Influenced by Debates?}

Prior literature suggests that the strength of voters' prior partisanship is likely to condition the impact of debates. For example, independent and undecided voters may be more likely than partisans to be influenced by campaign events, including debates (Geer, 1988; Hillygus and Jackman, 2003). There is also evidence that swing voters in some African contexts are more influenced by policy-related information (Weghorst and Lindberg, 2013) and are more likely to change their vote intention during the course of a campaign (Horowitz, 2017). Thus, debates should have the greatest positive effect when swing and weak partisan voters evaluate candidates who have performed well in the debates (H5).

By contrast, partisans may be likely to interpret debates in a manner that reinforces their prior political opinions (Geer, 1988) or to discard information from the debate that is inconsistent with their partisan views (Taber and Lodge, 2006). These expectations build upon dual-process models of information processing (Rahn, 1993) and theories of motivated reasoning (Kunda, 1990). According to the former, individuals process information through two processes: a heuristic process, in which individuals rely upon simple cues, and a systematic process, which involves conscious deliberation and evaluation (Rahn, 1993). Given that systematic processing requires more effort, partisan voters may rely on partisan heuristics when evaluating candidates in the debates (Rahn, 1993). Moreover, information processing is often guided by a desire to affirm partisan or social identity (Kunda, 1990). If partisan voters privilege such goals over accuracy, they will be motivated to scrutinize and evaluate new information in a way that reinforces, or even amplifies, prior beliefs (Taber and Lodge, 2006). Consequently, among strong partisans, debates may have a greater impact on support for the voter's co-partisan (H6). ${ }^{7}$

H5 and H6 capture our ex ante (pre-specified) expectations. However, there are several reasons why debates could also moderate partisan voters' political preferences. First, an alternative model of information processing holds that voters update their beliefs following Bayes' Rule (Bullock, 2009; Gerber and Green, 1999). Consistent with this, there is evidence that voters can accurately update their beliefs in light of policy information, even when that information is accompanied by party cues or is inconsistent with partisan priors (Boudreau and MacKenzie, 2014; Bullock, 2011). Although Bayesian learning can

\footnotetext{
${ }^{7}$ We also pre-specified hypotheses about how the impact of debates may be conditioned by political knowledge and how debates may influence attitudes towards tolerance, vote buying and electoral integrity. Appendix N (pg. 29) displays these results.
} 
be consistent with partisan disagreement (Bullock, 2009; Gerber and Green, 1999), in many contexts it is likely to generate partisan moderation. This is because Bayes' Rule implies that information is most likely to influence voters when it differs from their prior beliefs - when it is new or surprising (Dunning et al., Forthcoming). Since committed partisans are likely to have very negative prior beliefs about candidates from other parties, debates can provide new information to partisans about these candidates that is positive relative to their negative priors. Conversely, debates can provide partisans new information about co-partisans that generates disappointment given their strong positive priors. For example, partisans may be surprised about how well qualified opponents are or, equally, disappointed that their co-partisan's policy proposals are not as convincing as they originally believed. Together, these effects produce moderation; partisan voters' attitudes toward candidates become less polarized.

Second, partisan motivated reasoning may be less likely in new democracies compared to older ones because political parties are younger and often do not develop strong ideological platforms or differentiate on policy grounds (Van De Walle and Butler, 1999). Given this, voters may be more responsive to new information than they might be in contexts where partisanship is more clearly structured along ideological lines and partisan identities are stronger. Put simply, voters may not be motivated to privilege partisan goals over accuracy goals when processing new information. ${ }^{8}$ Thus, by providing information about candidate quality and policy positions, debates may provide new information about opposing party candidates that partisan voters find convincing.

Finally, the structure of debates - which simultaneously exposes voters to competing political perspectives - can prompt voters to better understand the rationales behind the perspectives of competitors, which can promote moderation (Mutz, 2002). Information provided by opposition candidates may be especially influential in newer democracies because voters may not be aware of the arguments of all parties. Thus, given their unique structure, the effect of debates may be distinct from other types of campaign events and forms of political information.

\footnotetext{
${ }^{8}$ Voters may be motivated to affirm other social identities, such as ethnicity, when processing new information (Adida et al., 2017). In the context of parliamentary debates in Ghana, ethnic and regional identities are usually constant across all candidates.
} 


\section{Parliamentary Elections and Debates in Ghana}

We conduct our study around the parliamentary elections held in Ghana in December 2016, the seventh since the return to democracy in 1992. One Member of Parliament (MP) serves each of the country's 275 political constituencies for a four-year term. The parliament is often composed only of MPs from the two major political parties - the National Democratic Congress (NDC) and the New Patriotic Party (NPP). The prominent minor parties are the Convention People's Party (CPP), the People's Progressive Party (PPP), and the People's National Convention (PNC). Although candidates from the minor parties usually fail to get elected, these parties receive about 5 percent of votes nationally.

While election campaigns in Ghana often involve clientelistic exchanges (Nathan, 2019), there is also evidence that voters consider policy issues and public service provision (Harding, 2015; Weghorst and Lindberg, 2013). Civil society organizations are increasingly coordinating programs designed to promote policy-based campaigning and to provide opportunities for voters to gather information about parliamentary candidates. CDD-Ghana began holding parliamentary debates during the 2012 election campaign. These debates are modeled on the televised presidential debates that have been held since 2000.

\section{The Debates}

CDD-Ghana and the NCCE organized parliamentary debates in 50 constituencies across Ghana's 10 regions during the 2016 elections. We conducted our study in three: Effutu, Komenda-Edina-EguafoAbirem (KEEA), and Mfantseman in the Central Region (See Figure 1). We selected these constituencies because they are a microcosm of Ghana's partisan landscape; each comprises communities that strongly support either the NDC or the NPP, as well as communities that are competitive. The Central region is also home to swing voters. Thus, while these constituencies are more electorally competitive than the 
average constituency in Ghana, ${ }^{9}$ they are ideal locations to test hypotheses about the effect of debates on partisan and swing voters. ${ }^{10}$

Table 1 displays the candidates' names and party affiliations. The debates were held in public locations and were attended by ordinary voters as well as party members, traditional authorities, and leaders of community organizations. The debates were broadcast on local radio stations and were covered in local newspapers. We videotaped the debates and then transferred the videos to smartphones to show study participants.

Figure 1 about here

Candidates spoke in the language of their choice. While most spoke exclusively in Fante (the dominant language in the Central Region), some spoke partly in English. ${ }^{11}$ Each debate had an identical structure. Candidates were in the same location and on the same stage when answering the moderator's questions, and often engaged with the statements of the other candidates. This study focuses on two of the three main debate segments. First, each candidate had two minutes to describe their personal background, qualifications, and values. We refer to this as the Personal Background segment. Second, the moderator asked each candidate to discuss their plans in two policy areas: education ( 2 minutes) and unemployment (2 minutes). We refer to this as the Policy segment. ${ }^{12}$

Table 1 about here

\subsection{Personal Background Segment}

In this segment, candidates discussed three broad topics: their familial heritage, their motivation to enter politics, and their qualifications. Most sought to establish their familial connections to local communities. For example, Ato Arthur (NPP), emphasized his roots in the constituency, stating that he is "a proud

\footnotetext{
${ }^{9}$ During the prior election (2012), the average margin of victory in parliamentary races in Central was 11 percentage points. This figure is comparable to other competitive regions in the country. The Central region is also typical in terms of the parliamentary vote share of minor parties: about four percent compared to an average of six percent across the other nine regions.

${ }^{10}$ In Appendix B we present results from a constituency-level analysis (pgs. 2-5). As debates were not randomly assigned to constituencies, these analyses are observational and should be interpreted with caution. Results suggest that debates have a negative association with incumbent vote share and a positive association with minor party vote share. Neither of these relationships are statistically significant.

${ }^{11}$ The study used only the candidates' original language; no translations were provided to participants.

${ }^{12}$ Candidates also fielded questions from audience members. To ensure uniform treatment across constituencies, our experiment did not include these discussions.
} 
son of Komenda; my mother and my father are from Abram-Boase, the former chief family head." Quandoh Okyere (PPP) noted that "[he] was born in Mankessim, [his] mother is from Mankessim-Twafo, [his] father was also born in Mankessim and so when they are talking about the indigenous people of Mankessim [he is] also part of them."

Many also articulated why they got involved in politics. The NPP candidate in Effutu, and incumbent in the district, Alex Afenyoh-Markin said: "Nobody introduced me to politics, I started politics on my own because growing up I saw the hardships we face here in Winneba, I see what poverty has done to people and so I promised myself that if God saves me from poverty, I will also come and save my people. That is why I joined politics."

All candidates detailed their academic qualifications and their professional experience. To demonstrate their commitment to local issues, most highlighted their involvement in local organizations or their past work to help the community.

\subsection{Policy Segment}

The policy segment focused on two salient issues in the 2016 campaign: education and unemployment. The candidates employed a mix of valence and policy-specific discourse during these segments. Regarding valence, one CPP candidate said, "When the CPP comes into power, the constant power instability will be a thing of the past ... the light problem is fixed: we will work and be comfortable." Another candidate said, "There will be a new era for entrepreneurship in Effutu. We will encourage entrepreneurs to establish their businesses in Winneba."

Most candidates also proposed specific policy plans (summarized in Table 2). For example, the NDC and NPP candidates offered distinct policies to improve access to secondary education. The NPP candidates, along with candidates from the CPP and PPP, promised to eliminate school fees for secondary school. For example, Ato Arthur (NPP, KEEA) argued that "the paramount reason why the children are unable to complete is the hardship that the parents face to pay for their school fees." By contrast, the NDC candidates emphasized their commitment to infrastructure development as a way to increase public access to secondary school. NDC candidates also challenged the NPP's proposal for universal free secondary school. For example, the NDC candidate in KEEA responded to the NPP candidate's 
education proposal by asking "if any government comes here to say that SHS [secondary school] is free, what school is here for the children to go to?"

Regarding employment policies, several candidates discussed the importance of providing skills training for young people. Others emphasized the need to re-open specific local factories to process poultry and locally grown cassava. Many candidates also highlighted their plans to support the fishing industry by constructing a new harbor.

\section{Table 2 about here}

\section{Research Design}

We designed the study to experimentally test hypotheses about why debates influence voters' attitudes. To test our hypotheses about causal mechanisms, we employ implicit mediation analysis (Gerber and Green, 2012). The design entails randomly assigning participants to different components of the treatment in our case, different segments of debates - which correspond to different potential causal channels. Comparing the causal effect of each segment allows us to identify which mechanism (or mechanisms) is responsible for the treatment effects that we identify. This approach avoids concerns about the potential bias involved in using intermediate variables to assess mechanisms (Gerber and Green, 2012; Imai et al., 2011).

Randomization was at the individual level. In one treatment condition, participants watched only the personal background segment; they learned about candidate quality, but not policy positions. In another treatment condition, participants only viewed the policy segment. In another condition, participants watched both segments. In the final condition, participants listened to both segments. Participants in the control group watched a non-political, placebo video that was roughly equal in length to the debate. ${ }^{13}$ Figure 2 displays the five treatment conditions and the number of respondents in each.

Our design permits experimental inferences about causal mechanisms. For example, if the policy segment has a larger impact than the personal background segment, this would provide evidence that policy-centered discussions are an important mechanism, as those in the personal background segment do not learn about policy positions. Alternatively, if the full debate video condition has a larger effect than

\footnotetext{
${ }^{13}$ The video was an extract from a show by a popular Ghanaian comedian.
} 
the full debate audio condition, this would suggest that visual information is important. We also note that candidates may convey quality during the policy segments. Thus, our design focuses on distinguishing the impact of policy-centered discussion from direct information about candidate quality that is conveyed during the personal background segment.

Figure 2 about here

As noted, the debates that we analyze were real campaign events. Accordingly, some respondents in our sample had heard about or seen them before we contacted them. About fifteen percent of respondents had pre-treatment exposure to the debates. Importantly for our analyses, these respondents are distributed equally across the control and treatment groups (see Appendix Tables D.1 and D.2, pgs. 7-8). Our results are also robust to excluding respondents who had prior exposure to the debates. ${ }^{14}$

\subsection{Sampling and Interview Procedure}

Our sampling procedure was guided by our goal to determine how partisanship conditions the impact of debates on voters. To ensure that the sample contained partisans of both major parties, as well as swing voters, we first stratified Electoral Areas (EAs) within each constituency. ${ }^{15}$ We classify EAs as being NPP strongholds, NDC strongholds or electorally competitive. ${ }^{16}$ We then randomly selected respondents from EAs within each of these three blocks. Appendix Tables D.1 and D.2 present descriptive information about the sample, including covariate balance across treatment and control groups.

After completing a short survey, participants watched (or listened to) the debate (or placebo video) associated with their treatment condition. Respondents viewed the debate on a smartphone. ${ }^{17}$ Enumerators gave the participant as much privacy as possible.

\subsection{Main Outcome Measures}

Our main outcome measures were collected through a survey conducted immediately after each participant viewed the debate (or control video). The first dependent variable is a continuous measure, ranging

\footnotetext{
${ }^{14}$ Relatedly, our design rules out the possibility that spillover effects within or across constituency boundaries will bias our results because outcome measures were collected immediately after our individual-level treatment.

${ }^{15}$ EAs are sub-constituency units.

${ }^{16}$ See Appendix $\mathrm{C}$ for further details on EA classification and sampling (pg. 6).

${ }^{17} \mathrm{~A}$ random number generator in the survey program assigned participants to one of the five conditions.
} 
from one to seven, of the participant's overall evaluation of each candidate in the debate: [What is] your overall assessment of [candidate name], who is the [political party name] candidate for parliament in [constituency name]. We also create a binary measure using the same question (positive evaluation), which takes a value of 1 if the overall evaluation is greater than 4 (a positive rating), and 0 otherwise. ${ }^{18}$

We also analyze a dichotomous (0/1) measure of vote choice. To limit response bias, the smartphone displayed logos and labels for each participating political party. Participants then privately selected which party's candidate they would vote for by tapping on the party logo. The exact wording of the prompt was: Please click on the party that you would vote for if the upcoming parliamentary elections were held today in [constituency name].

These outcome measures capture distinct but related outcomes. The evaluation measures capture whether debates lead voters to alter their assessments of candidates. The vote choice outcome assesses whether debates impact intended voting behavior. We emphasize that whether and how debates change citizens' evaluations of candidates is important even if debates do not change intended vote choice. For example, in polarized political contexts it is important to understand whether debates reduce - or increase - partisan bias in voters' evaluation of candidates, as this can have implications for partisan polarization and political stability.

\subsection{Coding Partisans and Swing Voters}

To measure partisanship, we use pre-treatment survey questions similar to "feeling thermometers." 19 To construct the partisan thermometer, we asked participants (pre-treatment) to rate, on a 1-7 scale, how close they feel to each of the major parties. We added these evaluations to produce a continuous scale. Voters with larger negative scores are closer to the NDC, and higher positive scores closer to the NPP. As pre-specified, we coded voters by cutting the distribution of this continuous variable at the 33rd and 66th percentiles, such that the bottom third of the distribution are NDC partisans, the top third of the distribution are NPP partisans, and the middle third are swing voters.

\footnotetext{
${ }^{18}$ This outcome was not pre-specified, but is included to assess whether treatment shifted evaluations from overall negative to overall positive.

${ }^{19}$ We also pre-specified a count measure of swing voters, adapting the measure of Weghorst and Lindberg (2013). Because many respondents had missingness in their voting history - usually because of their age - the count measure is not applicable to our full sample. None of the main results change if we use the count measure.
} 
A potential concern with generalizability is that partisans in Central may be different from partisans elsewhere, especially those in non-competitive regions. We note that while our sample contains a significant number of swing voters, it also contains a large proportion of very "strong partisans": those who evaluate their party with the maximum score and opponent parties with the minimum score on the partisan feeling thermometer. About 42 percent of the sample is a strong partisan by this definition. The results are robust and stronger in analyses that only contain strong partisans - the types of partisans that may be present in greater numbers in other regions of the country. In short, while our experimental sample is confined to the Central region - which we selected to ensure that we had the statistical power to assess our hypotheses on voter types — the results are likely to generalize to other areas of the country.

\subsection{Model Specification}

We created a dataset in which the unit of analysis is the participant-candidate dyad. Our baseline specifications are as follows:

$$
Y_{i j k}=\alpha+\beta_{0} * T_{i j}+\gamma_{j}+\theta X_{i j}+\varepsilon_{i j k}
$$

and

$$
Y_{i j k}=\alpha+\beta_{1} * T 1_{i j}+\beta_{2} * T 2_{i j}+\beta_{3} * T 3_{i j}+\beta_{4} * T 4_{i j}+\gamma_{j}+\theta X_{i j}+\varepsilon_{i j k}
$$

$Y_{i j k}$ is an outcome for participant $i$ in electoral area $j$ for candidate $k$. In Equation 1, we estimate the causal effect $\left(\beta_{0}\right)$ of receiving any of the debate treatments $\left(T_{i j}\right)$. In Equation 2, we separate by each treatment condition. $\gamma_{j}$ are fixed effects for each EA (our sampling units). These ensure that our inferences are driven by differences between voters who have the same candidate choices (and view the same debates), and should increase the efficiency of our estimates by controlling for differences across constituencies and local communities. As pre-specified and to improve precision (Gerber and Green, 2012), we also include the following pre-treatment covariates $(X)$ : age, gender, education, and employment status. Since participants enter into the data multiple times, we cluster standard errors on participants. To account for multiple comparisons, in Appendix F (pg. 12-15) we present adjusted p- 
values, which control for the False Discovery Rate (Benjamini and Hochberg, 1995). The main results are robust to these adjustments.

\section{Results}

\subsection{Average Treatment Effects in the Full Sample}

Panel A of Table 3 presents the mean evaluation of candidates in each of the five experimental conditions. The mean in the control group is 3.38 , and this increases to 3.59 in the pooled treatment group. The mean in each treatment group is also higher than in the control group: 3.56 for the Personal Background segment, 3.64 in Policy, 3.59 in Full Debate (video), and 3.58 in Full Debate (audio). ${ }^{20}$

Table 3 also presents average treatment effects (ATEs), estimated using Equations 1 and 2. Column 2 presents the average treatment effect pooling across all treatment conditions. Consistent with $H 1$, debates have a positive and statistically significant effect on voters' evaluations of candidates. The magnitude of the coefficient ( 0.19 on a 7 -point scale) is modest: about one-tenth of a standard deviation, or about a 6 percent increase from the control group mean.

Table 3 about here

Panel B of Table 3 displays the results using the binary positive evaluation measure. In the control group, 30 percent of candidates are rated positively. The average treatment effect pooling across all treatment conditions is 4.5 percentage points. This effect represents a 15 percent increase in the probability of a respondent positively evaluating a candidate, a substantively meaningful effect that further corroborates $H 1$.

Appendix Figure J.1 shows the effect of the debates on evaluations for each candidate separately (pg. 20). We find positive effects for 12 of the 13 candidates. In the full sample, respondents' evaluations of candidates from the CPP and the PPP increased the most after watching the debates. ${ }^{21}$ In summary, in the full sample, debates lead to modest improvements in respondents' evaluations of all candidates, especially those from minor political parties (see Appendix M, pg. 28).

\footnotetext{
20 The inclusion of the vote intention outcome in Tables 3 and 4 would not be informative because these analyses pool across all voter-candidate dyads. The vote intention outcome is only meaningful when we examine whether debates make voters more likely to support specific types of candidates.

${ }^{21}$ Appendix Table J.1 presents the results aggregated at the party level. The treatment effects for each party on a 7-point scale are as follows: 0.08 (NDC), 0.06 (NPP), 0.33 (CPP), 0.27 (PPP), and 0.06 (PNC).
} 
To investigate the mechanisms that drive the pooled average treatment effect in the full sample, we compare the effect of the policy treatment to the effect of the personal background treatment. Because participants are randomly assigned to these conditions and participants in the personal background condition do not receive information about policy, this comparison provides a causal estimate of the relative importance of these potential mechanisms. The results are presented in columns 3-4 of Table 3 . While each treatment has a positive and statistically significant effect, the magnitude of the policy segment effect $(0.23)$ is larger than that of the personal background segment $(0.16)$, which suggests that information about policy was more influential. However, the background and policy coefficients are not statistically different from one another, which suggests that both policy discussions and information about candidate quality drive the average effects.

To distinguish the effect of visual communication from the information contained in what candidates say, we compare the effect of the Full Debate Video treatment to the Full Debate Audio treatment (H3). There are no significant differences between the effects of these two conditions. This suggests that visual information is not driving the treatment effects.

\subsection{Results by Partisanship}

Table 4 disaggregates the sample between partisans and swing voters. Columns 1 and 2 show that the debates had no impact on swing voters. By contrast, the debates had a positive and significant impact on partisans (columns 3 and 4). Thus, the effects that we identify above are driven mainly by the impact of debates on partisans.

Table 4 about here

Nevertheless, we hypothesized that debates would lead swing voters to support candidates who performed well in the debates $(H 5)$. If swing voters reward good performers and punish poor performers, this would explain the small average effect in Table 4. Yet further analysis shows that swing voters are also no more likely to support the debate winner (see Appendix Table H.2, pg. 18). ${ }^{22}$

Regarding partisans, we hypothesized that debates would further increase their support for copartisan candidates. To test this hypothesis, Panel A of Table 5 presents treatment effects among all

\footnotetext{
${ }^{22}$ We code the debate winners using both an expert survey and the survey of study participants. See Appendix H (pg. 18).
} 
partisans. Columns 1 and 2 show the results for overall evaluations. The coefficient in row 1 is the treatment effect on evaluations of the co-partisan candidate, while the coefficient on the interaction term (row 2) shows how the effect changes when partisans evaluate opponents. To calculate the marginal effect on evaluations of opponent-party candidates, we add the coefficient in row 1 to the interaction coefficient in row 2. Contrary to our expectations, the debates did not affect partisans' evaluations of their co-partisan candidate.

Instead, we find a positive and significant effect on partisans' evaluations of opponent candidates. Using the results in column 1, we estimate that the debates increased partisans' evaluations of candidates from other parties by about 14 percent. In column 2, we restrict the sample to NDC and NPP candidates to assess whether this moderation effect is driven by changes in evaluations of minor party candidates, or whether NPP (NDC) partisans are becoming more favorable toward NDC (NPP) candidates. The magnitude of the effect remains positive but decreases in magnitude. While the coefficient is less precisely estimated because of the decreased sample size $(\mathrm{p}=0.19)$, the results suggest that the moderation effect is not driven entirely by minor party candidates. In Appendix Table K.2 we show that the debates made partisans 8 percentage points more likely to have a positive evaluation (defined above) of the candidate from the competing major party (pg. 25). This provides further evidence that partisan moderation is not driven entirely by partisans' evaluations of minor party candidates.

Table 5 about here

Panel A of Table 5 also shows that the treatment also significantly influenced the intended vote choice of partisans: debates made partisans 6 percentage points less likely to say they will vote for their party's candidate (column 3, row 1). In addition, partisans become about 2 percentage points more likely to report an intention to vote for another party. ${ }^{23}$ Given that national and legislative races are often decided by one or two percentage points, these effects are substantively large. Indeed, in 2016, about 17 percent of electoral constituencies had a margin of victory of less than 5 percent.

To show that these results are not being driven by the more moderate partisans in the sample, we further restrict our sample to strong partisans (see above for coding). Panel B of Table 5 shows that the moderation results remain the same or even larger among these strong partisans. Notably, column

\footnotetext{
${ }^{23}$ The estimate represents the marginal effect of treatment on partisans' preferences for the opponent candidates.
} 
2 shows that strong partisans of the NDC/NPP become significantly more supportive of the candidate from the other major party, ${ }^{24}$ while column 4 shows that they are about 2.5 percentage points more likely to intend to vote for the candidate from the other major party, a marginal effect that is statistically significant. ${ }^{25}$ The debates also made strong partisans 7 percentage points more likely to have a positive evaluation of the candidate from the other major party, a 54 percent increase (Appendix Table K.2, pg. 25).

Finally, to examine whether the moderation effects are driven by supporters of only one of Ghana's two major parties, in Appendices J.3 and J.4 we disaggregate the results by partisanship and candidate party. When examining all partisan voters, NDC partisans become significantly more favorable toward CPP candidates, while NPP partisans become more favorable toward NDC, CPP, and PPP candidates. This suggests that only NPP supporters moderate their attitudes toward the other major party, while partisans of both parties become more favorable toward minor party candidates. However, when we analyze the strong partisans, we find that both NPP and NDC supporters become more favorable toward the other major party candidate. Thus, we observe moderation toward the competing major party candidate among strong partisans of both major parties.

In summary, we find that partisanship conditions the effect of debates, although not in the way that we predicted. Debates make partisans both more favorable and more likely to vote for candidates from opposing parties, and less likely to vote for their co-partisan candidate. ${ }^{26}$

\subsection{What Drives Partisan Moderation?}

To investigate the drivers of partisan moderation, we first draw on our experimental design to estimate the effect of the personal background segment and the policy segment on partisan moderation. We restrict our analysis to include only partisans evaluating candidates from other parties. Table 6 reports the results. In column 1, the personal background and policy coefficients are both positive and significant.

\footnotetext{
${ }^{24}$ The marginal effect on evaluations is 0.39 and statistically significant.

${ }^{25}$ One potential concern with Table 5 is that partisans already have extremely high evaluations of their co-partisan candidate. However, while co-partisans' evaluations in the control group are high (a mean of 6.15), and the majority of partisans in control say they will vote for their co-partisan candidate ( 86 percent), both of these control group means have the potential to increase post-treatment. These levels of baseline support mitigate concerns of possible ceiling effects.

${ }^{26}$ Appendix Table D.3 examines whether partisan and swing voters differ on pre-treatment variables such as education, wealth, and age (pg. 9). We find no substantively important differences between these types of voters.
} 
The coefficient for the policy treatment is larger in magnitude, but is not statistically different from the personal background treatment coefficient $(0.45$ versus 0.34$)$. Thus, information on both candidate qualities and policy lead to increases in partisans' evaluations of opponent-party candidates.

Column 2 again restricts the analysis to strong partisans. ${ }^{27}$ Here, the personal background and policy coefficients are both positive and significant, but the policy coefficient is more than twice as large in magnitude (0.50 versus 0.22$)$. The magnitude of the policy coefficient is also substantively meaningful: a half a point increase on a 7-point scale. Furthermore, the policy coefficient is significantly larger than the personal background coefficient $(p=0.008)$. Thus, for the strongest partisans in the sample, the policy mechanism plays a larger role in shaping their evaluations of opponent-party candidates. These results highlight the potential for policy-centered debate to reduce partisan polarization in a new democracy.

Columns 3 and 4 present the results on intended vote choice. Among all partisans (column 3), none of the treatments increased the likelihood that they would vote for an opposition candidate. However, information about policy positions increases the share of strong partisans who intend to vote for opponent candidates by 3 percentage points - a roughly 30 percent increase over the control group mean (column 4). By contrast, information on candidates' personal background has no effect on vote intentions. $^{28}$

Appendix Table K.3 presents the results using the binary positive evaluation measure (pg. 26). Again, the policy treatment has a larger effect than the background treatment. For the strong partisans, the policy segments increase the probability of positively rating candidates from other parties by 10 percentage points, a 50 percent increase. By contrast, the effect of the background segment is a 3percentage point increase, a marginal effect that is statistically significantly lower than the marginal effect of the policy segment. In summary, the experimental evidence shows that policy-centered debate played an important role in driving partisan moderation. These results are consistent with the theoretical argument that some partisans update their beliefs based on the new information about competitors that they were exposed to and are willing to shed their partisan leanings to support alternative candidates.

Table 6 about here

\footnotetext{
${ }^{27}$ This analysis was not pre-specified and thus is exploratory.

${ }^{28}$ These two coefficients are not statistically significantly different, however.
} 


\subsubsection{Examining Partisan Moderation using Real-Time Response Data}

We further explore the drivers of partisan moderation by analyzing real-time data capturing voters' evaluations of candidates as they watched one of the debates. ${ }^{29}$ The respondents in this sample $(\mathrm{N}=244)$, who are separate from the main survey sample, watched the full debate on a tablet using a platform that records responses in real time. ${ }^{30}$ Figure 3 displays an image of the platform. Respondents were instructed to click every time that they either approved or disapproved of what the candidate was saying. Participants (irrespective of partisanship) were actively engaged in this exercise throughout the debate. ${ }^{31}$ These data are descriptive and illuminate which elements of the debates provoked a reaction from voters.

Figure 3 about here

We aggregate positive and negative responses for each individual to construct an overall assessment of each candidate during each debate segment. A positive overall score indicates that the respondent had more positive than negative reactions. We average these scores across NDC and NPP partisans. Figure 4 displays the results. The y-axis represents the average aggregate response of partisans during each segment; for example, a value of two shows that partisans had on average two more positive clicks than they did negative. The left plot displays the reactions of NDC partisans, while the right plot displays the reactions of NPP partisans.

Figure 4 suggests that partisan moderation occurred mainly during the policy segment. This is illustrated by trends in the gap between partisans' evaluations of their co-partisan candidate compared to the opponent candidate. In the personal background segment, partisans are quite polarized: their reactions are very positive toward their co-partisan and very negative toward the opposing party candidate. In the policy segments, this partisan gap decreases substantially. ${ }^{32}$

Figure 4 about here

The real-time response data also allow us to examine which statements provoked particularly positive or negative responses from participants. In the personal background segment, NDC partisans

\footnotetext{
${ }^{29}$ We use the debate from the Effutu constituency. To collect these data, we partnered with G2 Analytics.

${ }^{30}$ These data were collected at the same time as the larger survey and in the same three constituencies.

${ }^{31}$ With roughly 35 unique respondents, on average, clicking during any particular 30-second interval of the 40-minute debate. See Appendix Figures O.1 and O.2 (pgs. 30-31).

${ }^{32}$ In the personal background section, the average net positive clicks to co-partisans is 3 compared to a 1.5 net negative clicks for opponents; a difference of 4.5. In comparison, in the education section, this difference is 1.5, and in the employment section it is 1 . The corresponding figure for NPP partisans is a difference of 4 in the background section, and 1.75 and 1.5 in the two policy segments.
} 
responded very negatively when the NPP candidate discussed, rather immodestly, his sacrifice to the community when he became an MP instead of pursuing a career in the United Nations. Similarly, NPP partisans reacted negatively when the NDC candidate praised President John Mahama and rallied the crowd for a "one touch" (first-round) NDC win in the presidential election.

In the policy segments, partisans tempered their attitudes toward candidates from the other major party. For example, the NPP candidate's employment policies proved popular with NDC partisans. Similarly, the NPP candidate's proposal to encourage young entrepreneurs to set up businesses and bid for government contracts, and to boost the constituency's renowned but faltering theater arts and choral music industry, gained support from NDC partisans.

In sum, respondents seemed better able to assess candidates on the merit of their proposals when watching the policy segments.

\section{Do the Effects of Debates Persist?}

Finally, we assess whether the effects of debates persist over time. To do so, we conducted a follow-up survey with a random 10 percent of respondents from our original sample. This survey was conducted two days later by the same survey enumerator. ${ }^{33}$

Using this sub-sample, we first replicate the main results and find that the moderation effect is larger in magnitude in this sub-sample (see Appendix Table P.2). However, in the full sub-sample, the moderation effect dissipates after two days. Thus, while debates make partisan voters more positive toward candidates from competing parties immediately after a debate, on average, these effects diminish quickly. Further analysis reveals, however, that this decay is not universal but rather confined to voters who live in politically homogeneous communities.

To demonstrate this, we separate the sub-sample between those living in EAs we classified as competitive versus party strongholds. ${ }^{34}$ Figure 5 displays the results. ${ }^{35}$ The left panel displays the moderation effect immediately after the debates in both competitive and party stronghold EAs. The

\footnotetext{
${ }^{33}$ Participants for the follow-up survey were selected using a random number generator in the survey program. Appendix Table P.1 presents descriptive information about this sample, which was balanced between the treatment and control groups (pg. 32).

${ }^{34}$ See Appendix C (pg. 6). This exploratory analysis was not pre-specified.

${ }^{35}$ These results correspond to Columns 5 and 6 of Appendix Table P.2 (pg. 32).
} 
right panel shows the same results two days later. The moderation effect persists, and actually increases, on average, for partisan voters living in electorally competitive EAs, while it is short-lived in party strongholds. In short, the durability of debates' influence appears to be conditioned by where voters live, a finding that we discuss further in the next section. We also note that two days is a relatively short period of time. Therefore, it remains an empirical question how long the effects will persist in competitive areas. ${ }^{36}$

\section{Figure 5 about here}

\section{Discussion and Conclusion}

Using an experimental research design and unique observational data, we investigate whether and why candidate debates influence voters' attitudes toward parliamentary candidates in Ghana. Our most important results are that debates moderated the political attitudes of partisans, making them more favorable toward candidates from other parties and less likely to want to vote for co-partisan candidates from their party. We also show that the policy-centered components of the debates are important drivers of partisan moderation.

These results make several novel contributions and suggest several important areas of future research. First, the partisan moderation result contrasts with some of the literature on debates and political communication in the United States (Levendusky, 2013). We suggest that there are two related explanations for this moderation effect. First, because information is most likely to have an impact when it differs from what voters already believe, debates are most likely to provide new information that is positive about opponent party candidates and negative about co-partisans (relative to priors). Second, we suggest that the nature of partisan attachments in new democracies is such that voters are less inclined to engage in partisan motivated reasoning, which makes them more open to arguments about policy from opponent party candidates. Better understanding why debates moderate attitudes in new democracies, as well as in electoral authoritarian regimes (Platas and Raffler, 2018), is an important area for future research.

\footnotetext{
36 We also analyze the fifteen percent of the sample who had been exposed to the debates before entering the study. The results (Appendix G, pg. 16) show that treatment did not have an effect on these voters. This null effect could suggest persistence of the effect of the original debate on this sub-sample.
} 
Second, our findings on partisan moderation contrast with recent research that has found evidence of ethnic and partisan motivated reasoning in African contexts (Adida et al., 2017; Carlson, 2016; Horowitz and Long, 2016). Thus, it will also be important for future research to examine how the type of information and the mode of dissemination shapes the influence of political information on voter attitudes. Our evidence shows that the debate format, where voters hear directly from candidates and watch them engage with one another, encourages partisans to be more open to candidates from other parties. Future research could directly compare debates to other candidate-centered events, such as town hall meetings and rallies, and information from the news media or civil society campaigns.

Third, we find that partisan moderation is mainly driven by policy debate, especially for strong partisans. This result suggests that debates can play a role in increasing policy-based campaigning in new democracies. While parliamentary aspirants did engage in valence discourse, the format of the debates encouraged them to highlight the specific actions they planned to take to improve the livelihoods of constituents. The real time data suggests that voters are responsive to this type of localized policy information. Future research could more explicitly test the relative impact of valence versus policyspecific appeals in the context of candidate-centered events.

Finally, we find that, on average, debates' influence on voters does not persist, a finding that is consistent with studies on campaign advertising in the United States (Gerber et al., 2011; Hill et al., 2013). However, these results also demonstrate that the longer-run impact of campaign events can be conditional on the political environment in which voters live. Indeed the moderation effect persisted in electorally competitive communities, while it dissipated in non-competitive areas. There may be multiple explanations for this result. Those living in competitive communities may be exposed to (or select into) more diverse media and points of view, which could reinforce the influence of debates. In contrast, those in party stronghold communities may only be exposed to highly partisan information or to social pressure to support the dominant party, which could overtake the information absorbed in the debates. Alternatively, political parties may be able to respond more effectively to counteract the influence of debates in communities where they are electorally dominant (Arias et al., 2018; Humphreys and Weinstein, 2013). Future research should investigate the potential drivers of these contextual effects 
more directly. Such research will be important for determining the conditions under which debates have a durable influence on voters. 


\section{References}

Adida, Claire, Jessica Gottlieb, Eric Kramon and Gwyneth McClendon. 2017. "Reducing or Reinforcing In-Group Preferences? An Experiment on Information and Ethnic Voting." Quarterly Journal of Political Science 12(4):437-77.

Arias, Eric, Horacio Larreguy, John Marshall and Pablo Querubin. 2018. "Priors Rule: When do malfeasance revelation help or hurt incumbent parties?" Working Paper https: / scholar.harvard.edu/ files/jmarshall/files/mexico_accountability_experiment_v11.pdf.

Benjamini, Yoav and Yosef Hochberg. 1995. "Controlling the false discovery rate: A practical and powerful approach to multiple testing." Journal of the royal statistical society 57(1):289-300.

Besley, Timothy. 2006. Principled Agents? The Political Economy of Good Government. Oxford: Oxford University Press.

Bidwell, Kelly, Katherine Casey and Rachel Glennerster. 2016. "Debates: Voting and Expenditure Responses to Political Communication." Stanford Graduate School of Business Working Paper No. 3066 https://www.gsb.stanford.edu/gsb-cmis/gsb-cmis-download-auth/362906.

Bleck, Jaimie and Nicolas Van de Walle. 2013. "Valence issues in African elections: Navigating uncertainty and the weight of the past." Comparative Political Studies 46(11):1394-1421.

Boudreau, Cheryl and Scott A MacKenzie. 2014. "Informing the electorate? How party cues and policy information affect public opinion about initiatives." American Journal of Political Science 58(1):4862.

Bullock, John G. 2009. "Partisan bias and the Bayesian ideal in the study of public opinion." The Journal of Politics 71(3):1109-1124.

Bullock, John G. 2011. "Elite influence on public opinion in an informed electorate." American Political Science Review 105(3):496-515.

Carlson, Elizabeth. 2016. "Finding partisanship where we least expect it: evidence of partisan bias in a new African democracy.” Political Behavior 38(1):129-154.

Cruz, Cesi, Philip Keefer, Julian Labonne and Trebbi Francesco. 2018. "Making Policies Matter: Voter Responses to Campaign Promises." NBER Working Paper No. 24785.

URL: https: //www. nber.org/papers/w24785

Dunning, Thad, Guy Grossman, Macartan Humphreys, Susan D. Hyde and Craig McIntosh, eds. Forthcoming. Metaketa I: The Limits of Electoral Accountability. New York: Cambridge University Press.

Fujiwara, Thomas and Leonard Wantchekon. 2013. "Can Informed Public Deliberation Overcome Clientelism? Experimental Evidence from Benin." American Economic Journal: Applied Economics 5(4):241-55.

Geer, John G. 1988. "The effects of presidential debates on the electorate's preferences for candidates." American Politics Quarterly 16(4):486-501.

Gerber, Alan and Donald Green. 1999. "Misperceptions about perceptual bias.” Annual Review of Political Science 2(1):189-210. 
Gerber, Alan and Donald Green. 2012. Field Experiments: Design, Analysis, and Interpretation. New York: W.W. Norton.

Gerber, Alan S, James G Gimpel, Donald P Green and Daron R Shaw. 2011. "How large and long-lasting are the persuasive effects of televised campaign ads? Results from a randomized field experiment." American Political Science Review 105(1):135-150.

Harding, Robin. 2015. “Attribution and Accountability: Voting for Roads in Ghana.” World Politics 67(4):656-89.

Hill, Seth J, James Lo, Lynn Vavreck and John Zaller. 2013. "How quickly we forget: The duration of persuasion effects from mass communication." Political Communication 30(4):521-547.

Hillygus, D Sunshine and Simon Jackman. 2003. "Voter decision making in election 2000: Campaign effects, partisan activation, and the Clinton legacy." American Journal of Political Science 47(4):583596.

Horowitz, Jeremey and James D Long. 2016. "Strategic voting, information, and ethnicity in emerging democracies: evidence from Kenya.” Electoral Studies 44:351-361.

Horowitz, Jeremy. 2017. "Ethnicity and the Swing Vote in Africa's Emerging Democracies: Evidence from Kenya." British Journal of Political Science .

Humphreys, Macartan and Jeremy Weinstein. 2013. "Policing Politicians." Working Paper http: / / www . columbia.edu/ mh2245/papers1/scorecard2010.pdf.

Imai, Kosuke, Luke Keele, Dustin Tingley and Teppei Yamamoto. 2011. "Unpacking the black box of causality: Learning about causal mechanisms from experimental and observational studies." American Political Science Review 105(4):765-789.

Kunda, Ziva. 1990. “The Case for Motivated Reasoning.” Psychological Bulletin 108(3):480-98.

Lawson, Chappell, Gabriel S Lenz, Andy Baker and Michael Myers. 2010. "Looking like a winner: Candidate appearance and electoral success in new democracies." World Politics 62(04):561-593.

Levendusky, Matthew S. 2013. "Why do partisan media polarize viewers?” American Journal of Political Science 57(3):611-623.

Lindberg, Staffan I. 2010. "What accountability pressures do MPs in Africa face and how do they respond? Evidence from Ghana.” The Journal of Modern African Studies 48(01):117-142.

Lupu, Noam and Rachel Beatty Riedl. 2013. "Political parties and uncertainty in developing democracies." Comparative Political Studies 46(11):1339-1365.

Mutz, Diana C. 2002. "Cross-cutting social networks: Testing democratic theory in practice.” American Political Science Review 96(1):111-126.

Nathan, Noah. 2019. "Does Participation Reinforce Patronage? Policy Preferences, Turnout, and Class in Urban Ghana." British Journal of Political Science 49(1):229-55.

National Democratic Institute. 2014. Organizing and Producing Candidate Debates: An International Guide. National Democratic Institute. 
Pande, Rohini. 2011. "Can informed voters enforce better governance? Experiments in low-income democracies." Annual Review of Economics 3(1):215-237.

Platas, Melina and Pia Raffler. 2018. “The Limits of Partisanship: How Information Can Encourage Crossing Party Lines." Working Paper http://piaraffler.com/wp-content/uploads/2018/08/ Platas_Raffler_MTC_aug5.pdf.

Rahn, Wendy M. 1993. "The role of partisan stereotypes in information processing about political candidates." American Journal of Political Science 37:472-496.

Taber, Charles S. and Milton Lodge. 2006. "Motivated Skepticism in the Evaluation of Political Beliefs." American Journal of Political Science 50(3):755-69.

Van De Walle, Nicolas and Kimberly Smiddy Butler. 1999. "Political parties and party systems in Africa's illiberal democracies." Cambridge Review of International Affairs 13(1):14-28.

Wantchekon, Leonard, Gabriel Lopez-Moctezuma, Thomas Fujiwara, Cecilia Pe Lero and Daniel Rubenson. 2017. "Policy Deliberation and Voter Persuasion: Experimental Evidence from an Election in the Philippines." Working paper http://www.princeton.edu/ fujiwara/papers/phil_ajps.pdf.

Weghorst, Keith R. and Staffan I. Lindberg. 2013. "What Drives the Swing Voter in Africa?" American Journal of Political Science 57(3):717-43. 


\section{Tables and Figures}

Table 1: Names and party affiliations of parliamentary candidates in the debates

\begin{tabular}{llll}
\hline Party & \multicolumn{2}{c}{ Constituency } & \\
\hline & Effutu & KEEA & Mfantseman \\
\hline NDC & Eric Don-Arthur & Samuel Atta Mills* & James Essuon \\
NPP & Alexander Afenyoh-Markin* & Stephen Nana Ato Arthur & Ekow Hayford* \\
PPP & Nana Ofori Owusu & John Sterlin & Kwabena Amu Quandoh Okyere \\
CPP & Ebenezer Rolance Akumbea-Sam & Rose Austin Tenadu & Pius Ebo Dughan \\
PNC & Murtala Muhammed Umar & & \\
\hline
\end{tabular}

Notes: * Denotes the winners of the 2016 election. 
Table 2: Candidates' position issues during the policy segment

\begin{tabular}{l|l}
\hline Education & Employment \\
\hline $\begin{array}{l}\text { - Construct more schools, and build toilets and } \\
\text { libraries in every school }\end{array}$ & - Construct a new harbor at Winneba \\
- Free education up to age 18 & - Re-open processing factory at Ampem \\
- Set up a constituency fund to pay for mock & - Re-open poultry factory at Pomadze \\
examination fees and extra classes & \\
- Organize inter-school quiz competition to & \\
encourage reading & \\
- Institute a constituency-wide Best Teacher Award \\
- Institute inter-school reading competitions
\end{tabular}


Table 3: Average treatment effects (ATE) in full sample across all candidates

\begin{tabular}{|c|c|c|c|c|c|c|}
\hline \multicolumn{7}{|c|}{ Panel A: Overall evaluation (1-7) } \\
\hline & $\begin{array}{l}\text { Control } \\
\text { (1) }\end{array}$ & $\begin{array}{c}\text { Any treatment } \\
\text { (2) }\end{array}$ & $\begin{array}{l}\text { Personal background } \\
\text { (3) }\end{array}$ & $\begin{array}{l}\text { Policy segment } \\
\text { (4) }\end{array}$ & $\begin{array}{l}\text { Full debate (video) } \\
\text { (5) }\end{array}$ & $\begin{array}{c}\text { Full debate (audio) } \\
\text { (6) }\end{array}$ \\
\hline$\overline{\text { Mean }}$ & $\begin{array}{c}3.38 \\
(0.06)\end{array}$ & $\begin{array}{c}3.59 \\
(0.03)\end{array}$ & $\begin{array}{c}3.56 \\
(0.05)\end{array}$ & $\begin{array}{c}3.64 \\
(0.05)\end{array}$ & $\begin{array}{c}3.59 \\
(0.05)\end{array}$ & $\begin{array}{c}3.58 \\
(0.05)\end{array}$ \\
\hline ATE & & $\begin{array}{c}0.19 * * * \\
(0.05)\end{array}$ & $\begin{array}{l}0.16^{* * *} \\
(0.07)\end{array}$ & $\begin{array}{c}0.23 * * * \\
(0.07)\end{array}$ & $\begin{array}{c}0.18^{* * * *} \\
(0.07)\end{array}$ & $\begin{array}{l}0.18 * * \\
(0.07)\end{array}$ \\
\hline
\end{tabular}

Panel B: Positive Evaluation (binary)

\begin{tabular}{lcccccc} 
& $\begin{array}{c}\text { Control } \\
(1)\end{array}$ & $\begin{array}{c}\text { Any treatment } \\
(2)\end{array}$ & $\begin{array}{c}\text { Personal background } \\
(3)\end{array}$ & $\begin{array}{c}\text { Policy segment } \\
(4)\end{array}$ & $\begin{array}{c}\text { Full debate (video) } \\
(5)\end{array}$ & $\begin{array}{c}\text { Full debate (audio) } \\
(6)\end{array}$ \\
\hline Mean & 0.30 & 0.35 & 0.34 & 0.36 & 0.35 & 0.35 \\
& $(0.01)$ & $(0.01)$ & $(0.01)$ & $(0.01)$ & $(0.01)$ & $(0.01)$ \\
\hline \multirow{2}{*}{ ATE } & & $0.05^{* * *}$ & $0.04^{* *}$ & $0.05^{* * *}$ & $0.04^{* * *}$ & $0.05^{* *}$ \\
& & $(0.01)$ & $(0.01)$ & $(0.01)$ & $(0.01)$ & $(0.01)$ \\
\hline \hline
\end{tabular}

Notes: Observations are at the individual-candidate dyad $(N=8,186)$. The dependent variable in Panel A is on a 1-7 scale with higher numbers indicating more positive evaluations of candidates. The dependent variable in Panel $\mathrm{B}$ is a binary measure indicating that the evaluation of the candidate is positive (greater than 4 on the 1-7 scale). The analyses in Panel B were not pre-specified but are included to provide evidence on the substantive importance of the treatment effects. ATEs are estimated using linear regression including individual-level pre-treatment covariates and sampling area fixed effects (corresponding to Equations 1 and 2). Standard errors clustered by individual in parentheses. $* * * p<0.01,{ }^{* *} \mathrm{p}<0.05,{ }^{*} \mathrm{p}<0.1$. 
Table 4: Average Treatment Effects by Partisanship

\begin{tabular}{lcccc}
\hline \hline & $(1)$ & $(2)$ & $(3)$ & $(4)$ \\
& Swing & Swing & Partisans & Partisans \\
\hline Any treatment & 0.03 & & $0.26^{* * *}$ & \\
& $(0.12)$ & & $(0.06)$ & \\
Personal background & & 0.04 & & $0.22^{* * *}$ \\
& & $(0.14)$ & & $(0.07)$ \\
Policy & & 0.07 & & $0.33^{* * *}$ \\
& & $(0.14)$ & & $(0.07)$ \\
Full debate (video) & & 0.13 & & $0.22^{* * *}$ \\
& & $(0.14)$ & & $(0.07)$ \\
Full debate (audio) & & -0.07 & & $0.28^{* * *}$ \\
& & $(0.14)$ & & $(0.08)$ \\
Constant & $3.51^{* * * *}$ & $3.51^{* * *}$ & $3.41^{* * *}$ & $3.41^{* * *}$ \\
& $(0.34)$ & $(0.35)$ & $(0.20)$ & $(0.20)$ \\
\hline Observations & 2,496 & 2,496 & 5,690 & 5,690 \\
R-squared & 0.03 & 0.03 & 0.03 & 0.03 \\
\hline \hline
\end{tabular}

Notes: All models include individual-level pre-treatment covariates and sampling area fixed effects. Standard errors clustered by individual in parentheses. ${ }^{* * *} \mathrm{p}<0.01, * * \mathrm{p}<0.05, * \mathrm{p}<0.1$. 
Table 5: Treatment effects among NDC and NPP partisans

\begin{tabular}{|c|c|c|c|c|}
\hline PANEL A: All Partisans & $\begin{array}{c}\text { (1) } \\
\text { Evaluation } \\
\text { (All) }\end{array}$ & $\begin{array}{c}(2) \\
\text { Evaluation } \\
(\mathrm{NDC} / \mathrm{NPP})\end{array}$ & $\begin{array}{l}(3) \\
\text { Vote } \\
\text { (All) }\end{array}$ & $\begin{array}{c}(4) \\
\text { Vote } \\
\text { (NDC/NPP) }\end{array}$ \\
\hline Any treatment & $\begin{array}{l}-0.01 \\
(0.17)\end{array}$ & $\begin{array}{l}-0.00 \\
(0.12)\end{array}$ & $\begin{array}{l}-0.06^{*} \\
(0.03)\end{array}$ & $\begin{array}{l}-0.05^{*} \\
(0.02)\end{array}$ \\
\hline Any treatment $\mathrm{x}$ opponent candidate & $\begin{array}{l}0.39 * \\
(0.20)\end{array}$ & $\begin{array}{c}0.26 \\
(0.20)\end{array}$ & $\begin{array}{c}0.08 * * \\
(0.04)\end{array}$ & $\begin{array}{l}0.05^{*} \\
(0.03)\end{array}$ \\
\hline Opponent candidate & $\begin{array}{c}-3.35 * * * \\
(0.18)\end{array}$ & $\begin{array}{c}-3.58 * * * \\
(0.18)\end{array}$ & $\begin{array}{c}-0.80 * * * \\
(0.03)\end{array}$ & $\begin{array}{c}-0.83 * * * \\
(0.03)\end{array}$ \\
\hline Constant & $\begin{array}{c}6.15^{* * *} \\
(0.24)\end{array}$ & $\begin{array}{c}6.56^{* * * *} \\
(0.22)\end{array}$ & $\begin{array}{c}0.86 * * * \\
(0.03)\end{array}$ & $\begin{array}{c}0.88 * * * \\
(0.04)\end{array}$ \\
\hline $\begin{array}{l}\text { Observations } \\
\text { R-squared }\end{array}$ & $\begin{array}{c}5,690 \\
0.37\end{array}$ & $\begin{array}{c}2,640 \\
0.49\end{array}$ & $\begin{array}{c}5,742 \\
0.60\end{array}$ & $\begin{array}{c}2,632 \\
0.64\end{array}$ \\
\hline PANEL B: Strong Partisans & $\begin{array}{c}\text { (1) } \\
\text { Evaluation } \\
\text { (All) }\end{array}$ & $\begin{array}{c}(2) \\
\text { Evaluation } \\
\text { (NDC/NPP) }\end{array}$ & $\begin{array}{c}(3) \\
\text { Vote } \\
\text { (All) }\end{array}$ & $\begin{array}{c}(4) \\
\text { Vote } \\
(\mathrm{NDC} / \mathrm{NPP})\end{array}$ \\
\hline Any treatment & $\begin{array}{l}-0.17 \\
(0.11)\end{array}$ & $\begin{array}{l}-0.14 \\
(0.10)\end{array}$ & $\begin{array}{c}-0.06 * * * \\
(0.02)\end{array}$ & $\begin{array}{c}-0.06 * * * \\
(0.02)\end{array}$ \\
\hline Treatment $\mathrm{x}$ opponent candidate & $\begin{array}{c}0.56 * * * \\
(0.16)\end{array}$ & $\begin{array}{c}0.45 * * \\
(0.19)\end{array}$ & $\begin{array}{c}0.08 * * * \\
(0.02)\end{array}$ & $\begin{array}{c}0.08 * * * \\
(0.02)\end{array}$ \\
\hline Opponent candidate & $\begin{array}{c}-4.56 * * * \\
(0.14)\end{array}$ & $\begin{array}{c}-4.71 * * * \\
(0.17)\end{array}$ & $\begin{array}{c}-0.97 * * * \\
(0.02)\end{array}$ & $\begin{array}{c}-0.97 * * * \\
(0.01)\end{array}$ \\
\hline Constant & $\begin{array}{c}6.80 * * * \\
(0.28)\end{array}$ & $\begin{array}{c}7.08 * * * \\
(0.29)\end{array}$ & $\begin{array}{c}0.97 * * * \\
(0.01)\end{array}$ & $\begin{array}{c}0.94 * * * \\
(0.04)\end{array}$ \\
\hline $\begin{array}{l}\text { Observations } \\
\text { R-squared }\end{array}$ & $\begin{array}{c}3,435 \\
0.56\end{array}$ & $\begin{array}{c}1,596 \\
0.71\end{array}$ & $\begin{array}{c}3,532 \\
0.83\end{array}$ & $\begin{array}{c}1,622 \\
0.84\end{array}$ \\
\hline
\end{tabular}

Notes: Partisanship is coded in reference to the respondent: that is, opponents candidates are those who are not aligned with the respondent's preferred party (pre-treatment). Observations are at the individual-candidate dyad. Columns (1) and (3) include all candidates. Columns (2) and (4) only include candidates from the NPP and NDC. The evaluation variable is on a 1-7 scale with higher numbers indicating more positive evaluations of candidates. The vote choice variable is dichotomous. All models include individual-level pre-treatment covariates and sampling area fixed effects. Standard errors clustered by individual in parentheses. $* * * \mathrm{p}<0.01, * * \mathrm{p}<0.05, * \mathrm{p}<0.1$. 
Table 6: Analysis of mechanisms when partisan voters evaluate candidates from other parties.

\begin{tabular}{lcccc}
\hline \hline & $(1)$ & $(2)$ & $(3)$ & $(4)$ \\
& $\begin{array}{c}\text { Evaluation } \\
\text { (All partisans) }\end{array}$ & $\begin{array}{c}\text { Evaluation } \\
\text { (Strong partisans) }\end{array}$ & $\begin{array}{c}\text { Vote } \\
\text { (All partisans) }\end{array}$ & $\begin{array}{c}\text { Vote } \\
\text { (Strong Partisans) }\end{array}$ \\
\hline Personal background & $0.34^{* * *}$ & $0.22^{* * *}$ & 0.01 & 0.01 \\
& $(0.10)$ & $(0.11)$ & $(0.01)$ & $(0.01)$ \\
Policy & $0.45^{* * *}$ & $0.50^{* * *}$ & 0.00 & $0.03 * *$ \\
Full debate (video) & $(0.10)$ & $(0.11)$ & $(0.01)$ & $(0.01)$ \\
& $0.31^{* * *}$ & $0.33^{* * *}$ & 0.01 & 0.02 \\
Full debate (audio) & $(0.10)$ & $(0.11)$ & $(0.01)$ & $(0.01)$ \\
& $0.39^{* * *}$ & $0.28^{* *}$ & 0.01 & 0.00 \\
Constant & $(0.11)$ & $(0.12)$ & $(0.01)$ & $(0.01)$ \\
& $2.78^{* * *}$ & $2.76^{* * *}$ & $0.04 * *$ & $0.10^{* * *}$ \\
Observations & $(0.27)$ & $(0.29)$ & $(0.02)$ & $(0.03)$ \\
R-squared & 4,199 & 3,129 & 4,291 & 3,223 \\
\hline \hline
\end{tabular}

Notes: The sample is restricted to include only partisan voters evaluating candidates from other parties. Observations are at the individual-candidate dyad. All models include individual-level pre-treatment covariates and sampling area fixed effects. Standard errors clustered by individual in parentheses. ${ }^{* * *} \mathrm{p}<0.01,{ }^{* *} \mathrm{p}<0.05$, * $\mathrm{p}<0.1$. 
Figure 1: Map of study constituencies

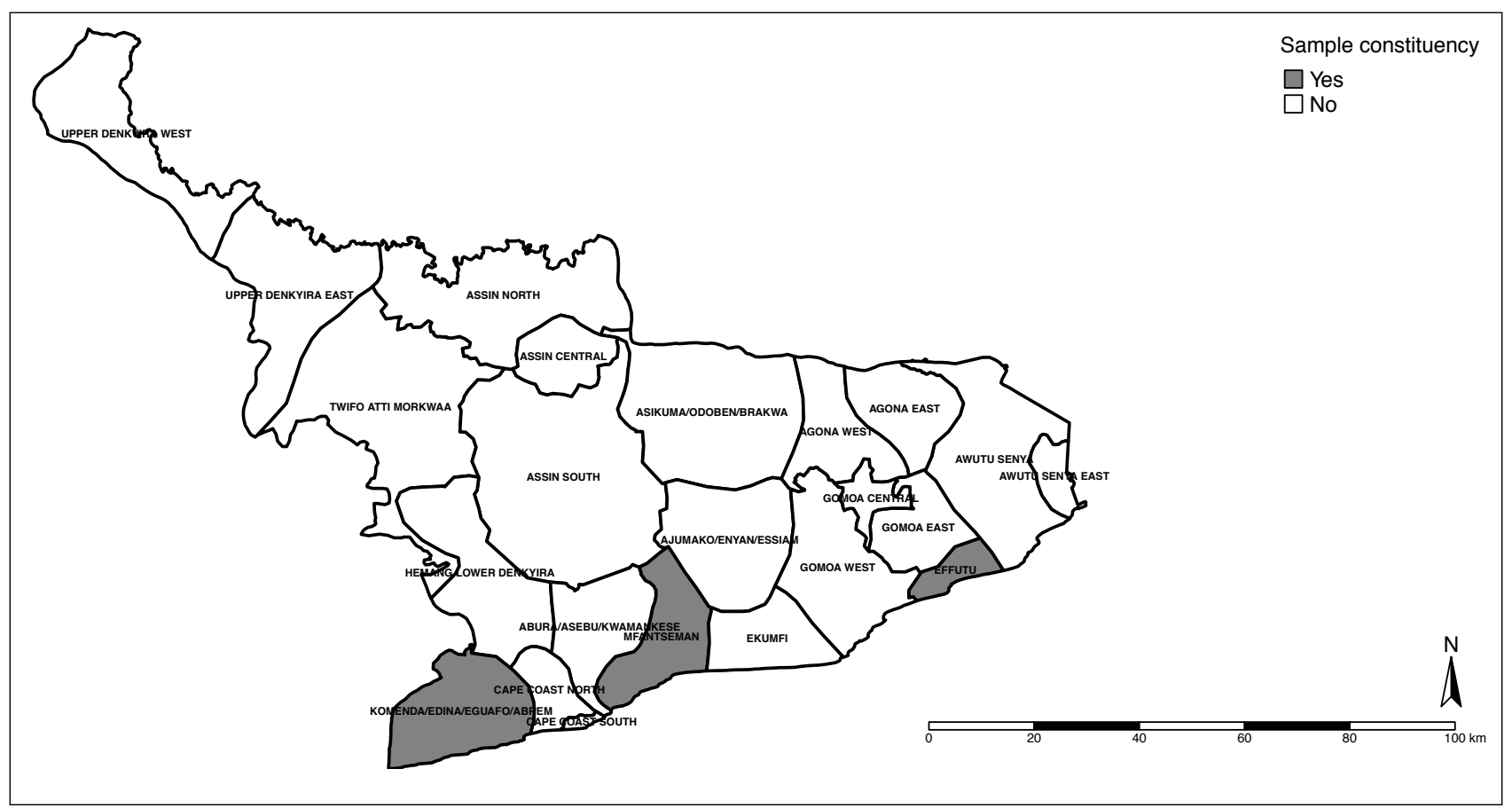

Notes: The figure displays a map of Central region with our three study constituencies highlighted in grey. 
Figure 2: Distribution of participants across treatment conditions

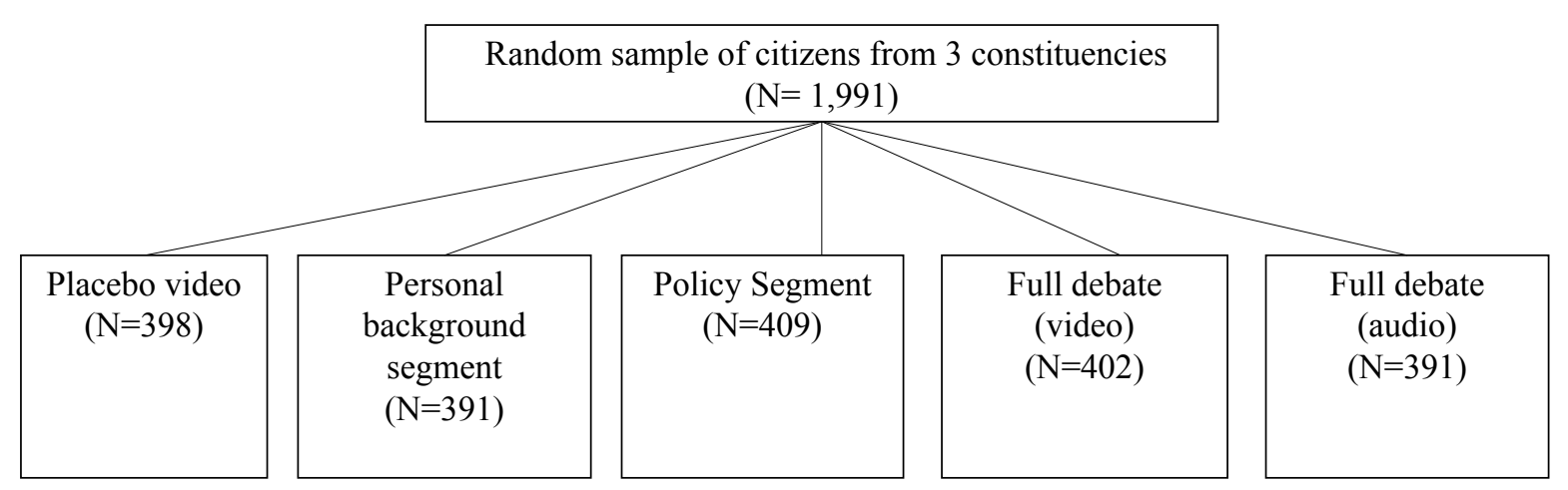

Notes: Each respondent had a 20 percent chance of being randomized into each of the five treatment conditions. 
Figure 3: Real time response platform

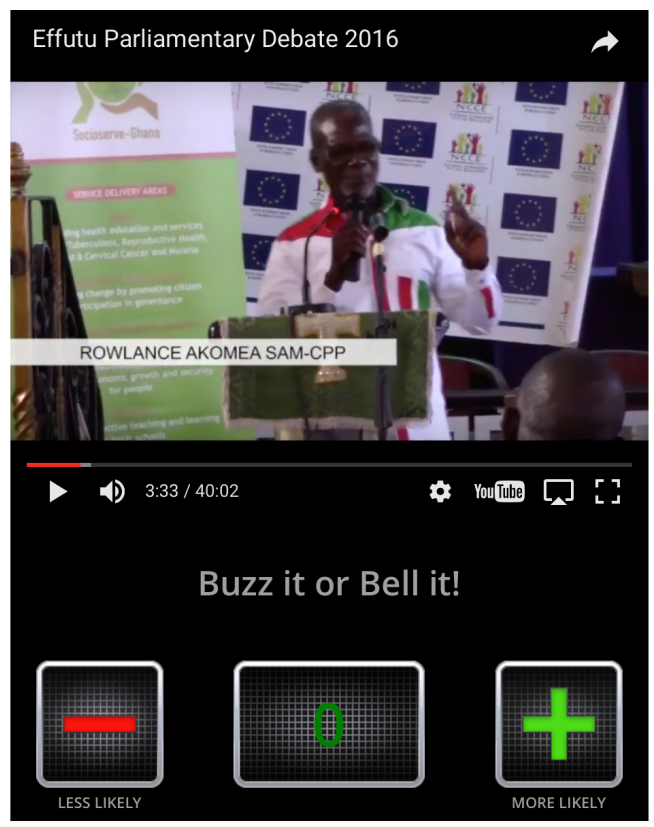

Notes: Photo of G2 Analytics real-time response platform. 
Figure 4: Aggregate real-time evaluations of co-partisan and opponent candidates (partisans only)

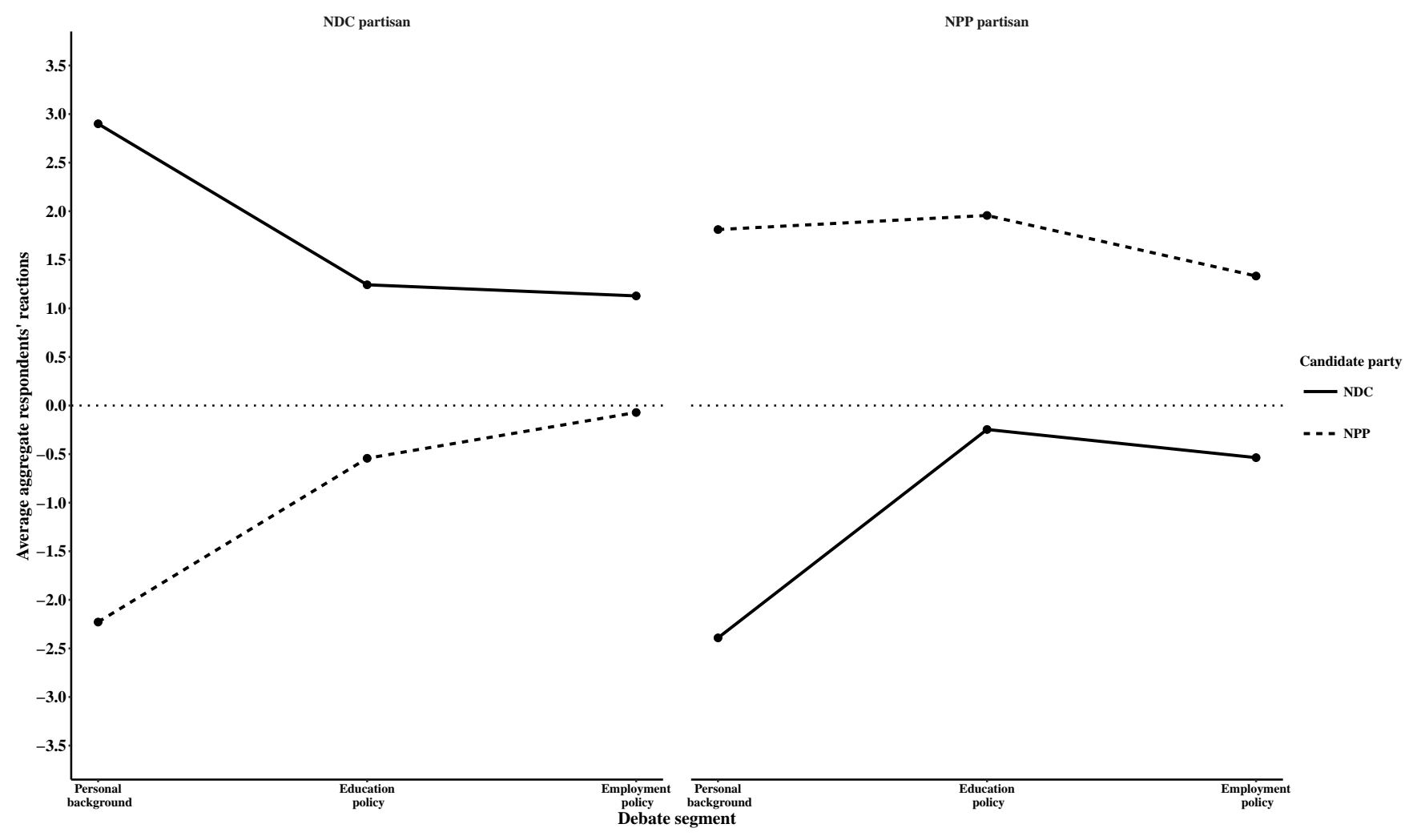


Figure 5: Moderation effects by partisan composition of the electoral area
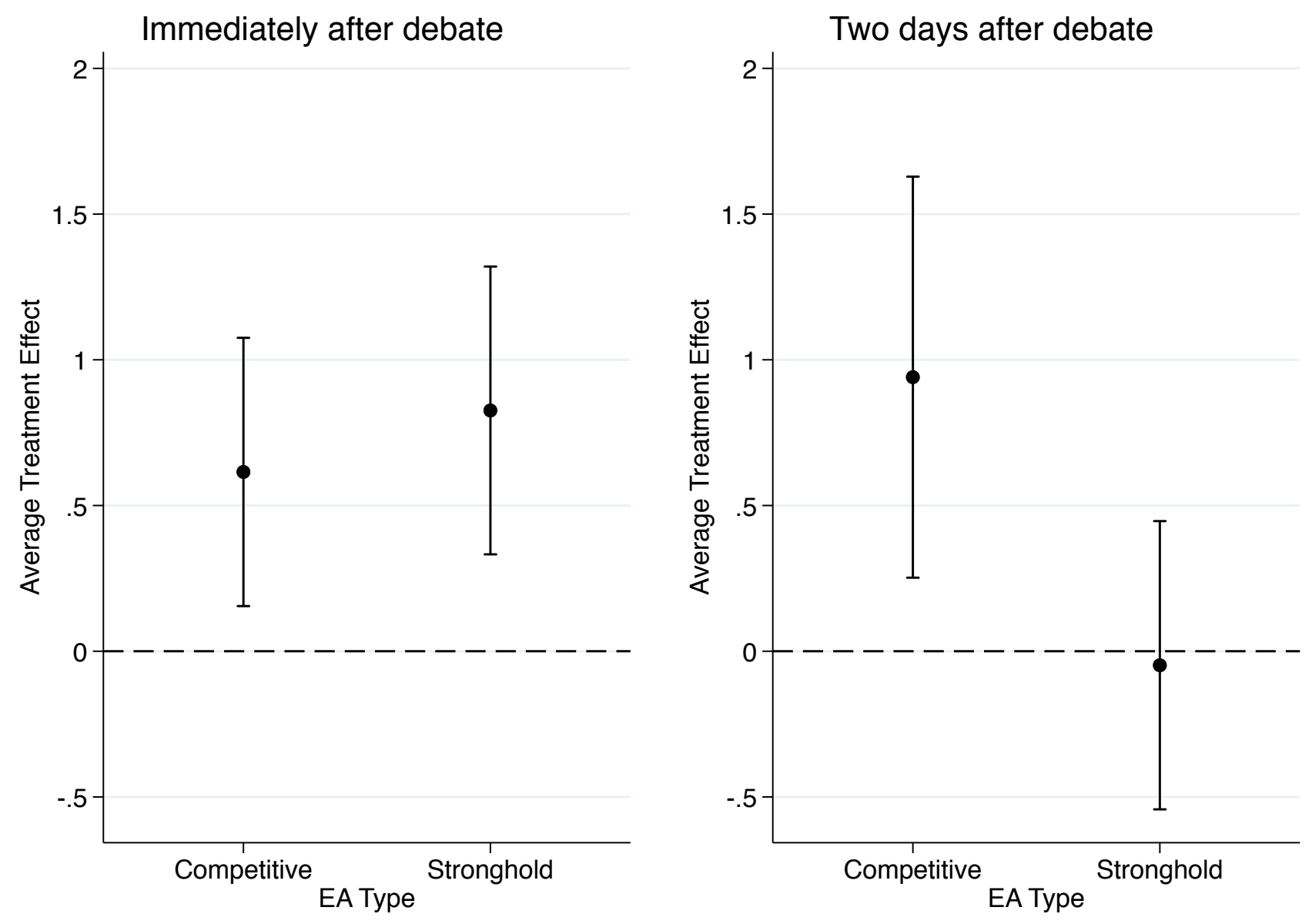

Notes: Figure 5 displays the treatment effect of debates when partisan voters evaluate candidates from opposing parties. Results are separated by electorally competitive and party stronghold EAs. The results correspond to the regression results in Columns 5 and 6 of Appendix Table P.2 (pg. 32). 